\title{
Leishmania mexicana recombinant filamentous acid phosphatase as carrier for Toxoplasma gondii surface antigen 1 expression in Leishmania tarentolae
}

\author{
Dalia Ahmed Kalef ${ }^{1}$ (D)
}

Received: 5 March 2021 / Accepted: 7 June 2021 / Published online: 17 June 2021

(C) Indian Society for Parasitology 2021

\begin{abstract}
Leishmania tarentolae has been used to produce recombinant intracellular and secreted proteins for their easy handling and posttranslational modifications. Filamentous acid phosphatase is a multimeric protein complex composed of many subunits assembled in a linear highly glycosylated filament, which is secreted in vast amounts into the culture supernatant via the flagellar pocket of Leishmania mexicana promastigotes. This suggested that the protein could be used as a carrier for the Surface Antigen1 protein of a Toxoplasma gondii (SAG1) for easy purification to generate a protein with multiple SAG1 subunits suitable for immunisation. SAG1 has an immunodominant structure that is involved in binding to host cells. Previous studies used this surface protein for vaccination for its immunological importance for triggering a type 1 immune response in the host. This study aims to determine the production of recombinant filamentous protein carried subunits of the surface protein of Toxoplasma gondii for vaccination purposes. Leishmania codon-optimised SAG1 was cloned as a fusion construct into pLEXSY-ble2.1 plasmid and introduced into Leishmania tarentolae to generate recombinant cell lines expressing a filamentous fusion protein called SAP2SAG1. PCR confirmed the correct integration into the small ribosomal subunit RNA gene locus of Leishmania tarentolae. Immunofluorescences and Immunoblot analyses were used to detect the fusion protein in the sediment of culture supernatants of recombinant $L$. tarentolae promastigotes after purification by ultracentrifugation. The yield of
\end{abstract}

Dalia Ahmed Kalef

dalia.a@covm.uobaghdad.edu.iq; daliaahmed@gmail.com

1 Department of Parasitology, University of Baghdad, Baghdad city, Iraq purified protein was low that suggested further investigations of other methods for scaling large production of secreted protein.

Keywords SAG1 · Leishmania tarentolae.

Filamentous recombinant protein · Protein expression

$\begin{array}{ll}\text { Abbreviations } \\ \text { Amp } & \text { Ampicillin } \\ \text { BSA } & \text { Bovine serum albumin } \\ \text { bp } & \text { Base pairs } \\ \text { ddH }{ }_{2} \mathrm{O} & \text { Double distilled water } \\ \text { DTT } & \text { 1,4-Dithiothreitol } \\ \text { DMEM } & \text { Dulbecco's modified eagle medium } \\ \text { DNA } & \text { Deoxyribonucleic acid } \\ \text { dNTP } & \text { Deoxyribonucleotide triphosphate } \\ \text { EDTA } & \text { Ethylene diamine tetraacetic acid } \\ \text { FCS } & \text { Foetal calf serum } \\ \text { GPI } & \text { Glycosyl phosphatidy linositol } \\ \text { gDNA } & \text { Genomic DNA } \\ \text { HRP } & \text { Horse radish peroxidase } \\ \text { kDa } & \text { Kilo-Dalton } \\ \text { LB } & \text { Luria-Bertani (broth) } \\ \text { ORF } & \text { Open reading frame } \\ \text { PBS } & \text { Phosphate buffered saline } \\ \text { PCR } & \text { Polymerase chain reaction } \\ \text { PVDF } & \text { Polyvinylidene fluoride } \\ \text { RFLP } & \text { Restriction fragment length polymorphisms } \\ \text { RNA } & \text { Ribonucleic acid } \\ \text { RPM } & \text { Revolutions per minute } \\ \text { SDS } & \text { PAGE sodium dodecyl sulphate polyacrylamide } \\ & \text { gel electrophoresis } \\ \text { SSU } & \text { Small ribosomal Subunit } \\ & \end{array}$




\section{Background}

\section{SAP2 Protein of Leishmania mexicana}

Leishmania mexicana is a protozoan parasite of the genus Leishmania, which are the causative agents of a range of diseases called leishmaniasis mostly found in tropical and subtropical regions (Dey et al. 2014). L. mexicana insect stage (promastigotes) secrete a filamentous protein of long acid phosphatases (SAP2). SAP2 protein is composed of 383 serine/threonine amino acids rich regions that are enzymatically active and assemble filaments in the flagellar pocket of the promastigotes. Besides, SAP2 protein has a long linear epitope in the $\mathrm{COOH}$-terminal tail that can detect by using monoclonal antibody (mAb) LT8.2.

\section{Leishmania tarentolae}

Leishmania tarentolae is a non-pathogenic trypanosomatid protozoan parasite living as promastigotes in the lumen of the intestine of lizards such as the gecko (Tarentola annularis) (Wilson and Southern 1979). L. tarentolae is distinguished by lacking 250 genes that are expressed in the intracellular amastigote stage. Hence, L. tarentolae has been used for heterologous gene expression and recombinant protein production (Raymond et al. 2012). L. tarentolae has been used as a protein expression system for both cytoplasmic and secreted proteins. Therefore, this work aims to determine the effectiveness of a novel eukaryotic filamentous protein expression system based on the $L$. mexicana SAP2 in $L$. tarentolae for vaccine development.

\section{Toxoplasma gondii surface antigen 1 (SAG1) protein}

Surface antigen 1 (SAG1) is considered the major surface antigen in $T$. gondii and comprises more than $5 \%$ of the total amount of protein of the tachyzoite stage of $T$. gondii (Lekutis et al. 2001). SAG1 is a tachyzoite that facilitates the adhesion and invasion of the host cells (Tang et al. 2016). SAG1 exists as a monomer of 250 amino acids with an approximate molecular weight of $30 \mathrm{kDa}$. It can form homodimer structures, which are attached to the parasite surface by glycosylphosphatidylinositol (GPI) anchors (He et al. 2002). Previous studies have focused on SAG1 for vaccination because it has a critical importance for the immune response in the initial stage of infection involving both the humoral and cellular immune response (Abdizadeh et al. 2015; Lekutis et al. 2001). Vaccination of mice with SAG1 has provided encouraging results with significant protection as measured by a reduction of the number of cysts in vaccinated animals compared with control animals (Lekutis et al. 2001). SAG1 was purified from tachyzoites and produced as a recombinant protein in E. coli or yeast (Wang and Yin 2014).

The aim of this was preparation and expression of recombinant protein of filamentous secreted acid phosphatase 2 fused with SAG1 (SAP2SAG1) in L. tarentolae for immunogenic importance in vaccination studies.

\section{Methods}

\section{Generation and purification of expression plasmid}

A single positive colony was inoculated to $100 \mathrm{ml}$ of LB broth with Carbenicillin $(100 \mu \mathrm{g} / \mathrm{ml})$ and incubated $16-18 \mathrm{~h}$ at $37{ }^{\circ} \mathrm{C}, 220 \mathrm{rpm}$. The plasmid DNA was purified from the overnight culture by using the Nucleobond $\AA$ Xtra Midi High copy plasmid protocol (Macherey-Nagel, Germany) until the elution step following the manufacturer's instructions. DNA pellets were resuspended in a total

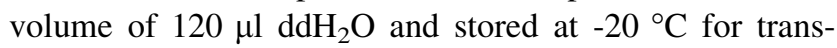
fection into $L$. tarentolae cells.

\section{Leishmania cell culture}

L. mexicana and $L$. tarentolae wild type promastigotes were grown at $27{ }^{\circ} \mathrm{C}$ without $\mathrm{CO}_{2}$ in complete SDM79 media and re-inoculated every 3-4 days. Leishmania promastigotes were counted by using a haemocytometer under a light microscope $(40 \times$ objective lens), and the averaged of cells were calculated per millilitre (number of cells/ $\mathrm{ml}=$ number of counted cells $\times$ dilution factor $(100)$ $\left.\times 10^{4}\right)$.

\section{Transfection of DNA into Leishmania tarentolae by using electroporation}

Transfection of linearised DNA into L. tarentolae cells was performed using a Nucleofector II (Amaxa Biosystems, Lonza, Germany). A maximum volume of $10 \mu \mathrm{l}$ of purified linearised plasmid DNA was mixed with the electroporation buffer before the cells were resuspended in it. L. tarentolae promastigotes were grown until a density of approximately $3 \times 10^{7}$ cells $/ \mathrm{ml}$. The cells were harvested by centrifugation for $2 \mathrm{~min}$, at $5600 \times \mathrm{g}$ and $4{ }^{\circ} \mathrm{C}$. The supernatant was gently removed from sedimented $L$. tarentolae cells and immediately replaced with $100 \mu \mathrm{l}$ electroporation buffer by gentle pipetting. The re-suspended cells were transferred to a pre-cooled electroporation cuvette with no air bubbles present. Cells were electroporated using Nucleofector II program V-033 or X-001 and left on ice for $10 \mathrm{~min}$. Electroporated cells were transferred from the cuvette to $10 \mathrm{ml} \mathrm{SDM79}$ medium supplemented with $8 \% \mathrm{v} / \mathrm{v}$ heat-inactivated fetal calf serum, $0.3 \% \mathrm{v} / \mathrm{v}$ hemin 
and incubated at $27{ }^{\circ} \mathrm{C}$ for $24 \mathrm{~h}$. On the second day, the electroporated cells were diluted 1:40 with supplemented SDM79 medium and the appropriate selective antibiotic was added to the diluted cell cultures. 1:40 dilutions were pipetted into 96 well plates using a multichannel pipette (200 $\mu \mathrm{l}$ per well) and incubated at $27{ }^{\circ} \mathrm{C}$ for $10-14$ days until turbid wells indicated growth of cloned parasites. Turbid wells were checked using an inverted microscope to confirm the presence of Leishmania cells in the well. $200 \mu \mathrm{l}$ of positive clones identified on the 96 well plates were transferred to 12 well plates containing $2 \mathrm{ml}$ supplemented SDM79 medium with the appropriate selective antibiotic and incubated at $27{ }^{\circ} \mathrm{C}$ for $72 \mathrm{~h}$ until turbidity was visibly observed in the well. Subsequently, $40 \mu \mathrm{l}$ from positive clones identified in 12 well plates were used to inoculate $10 \mathrm{ml}$ of supplemented SDM79 medium with the selective antibiotic and cultured at $27{ }^{\circ} \mathrm{C}$ for approximately $96 \mathrm{~h}$ until the culture reached the logarithmic growth phase.

\section{Isolation of genomic DNA from cloned L. tarentolae cells}

The "isolate II genomic DNA kit from Bioline, UK" was used to isolate genomic DNA from $L$. tarentolae cells following the manufacturer's instructions. $3 \mathrm{ml}$ of a stationary phase culture of Leishmania promastigotes (approximately $10^{7}$ parasites) was used. Genomic DNA pellets were resuspended in $100 \mu \mathrm{l}$ TE buffer, the concentration was determined using a NanoDrop2000 ${ }^{\circledR}$ (Thermo Scientific, Wilmington USA), and stored at $4{ }^{\circ} \mathrm{C}$ until required.

\section{Polymerase chain reaction (PCR)}

PCRs were performed using the Expand High Fidelity PCR System from Roche. 2 Reactions were carried out in a $25 \mu \mathrm{l}$ PCR tube using a $P E$ thermocycler. The sequences of LeishSSU forward (5'-GATCTGGTTGATTCTGCCAGTAG-3') and pLexyup1 reverse primers (5'-CCTACGTCAATCGCAGACCT-3') were used in the first reaction to confirm the correct integration of SAP2SAG1 construct into the rRNA gene locus. While in the second reaction the forward primer was SAP2mod2C (5'- AGCGACGTCCCTTCCTTCAA-3') and the reverse was SAG1-2 rev (5'-CCACTACTGCAGCGGCACGA-3') to approve the fusion of SAP2 and SAG1. The reaction mixture was composed of: template 10-200 $\mathrm{ng}$, forward primer $(10 \mu \mathrm{M}) 1 \mu \mathrm{l}$, reverse primer $(10 \mu \mathrm{M}) 1 \mu \mathrm{l}$, $10 \times$ PCR buffer $\left(15 \mathrm{mM} \mathrm{MgCl}_{2}\right) 5 \mu \mathrm{l}$, dNTPs $(10 \mathrm{mM})$ $1 \mu \mathrm{l}$, HiFidelity DNA Polymerase $0.8 \mu \mathrm{l}, \mathrm{ddH}_{2} \mathrm{O}$ was used to attain a final volume to $25 \mu \mathrm{l}$. PCR temperature Sequence: initial denaturation step $94{ }^{\circ} \mathrm{C} 3 \mathrm{~min}$, then 30 cycles consisting of $94{ }^{\circ} \mathrm{C}$ for $45 \mathrm{~s}, 52{ }^{\circ} \mathrm{C}$ for $30 \mathrm{~s}, 72{ }^{\circ} \mathrm{C}$ for $60 \mathrm{~s}$ and a final extension step at $72{ }^{\circ} \mathrm{C}$ for $7 \mathrm{~min}$ and then $4{ }^{\circ} \mathrm{C}$.

\section{Secreted acid phosphatase assay}

An acid phosphatase assay was used for detection of the protein expression in Leishmania cell-free culture supernatants, which were prepared from $25 \mu$ culture at the late logarithmic stage by sedimentation at $5600 \times \mathrm{g}, 4{ }^{\circ} \mathrm{C}$, $2 \mathrm{~min}$. The total volume per well of a 96-well plate was $100 \mu \mathrm{l}$ composed of a $20 \mu \mathrm{l}$ supernatant/media sample, $70 \mu \mathrm{l}$ (50 mM $p$-nitrophenyl phosphate in $100 \mathrm{mM}$ sodium acetate $\mathrm{pH}$ 5.0). The plate was incubated at $37{ }^{\circ} \mathrm{C}$ for $30 \mathrm{~min}$. The reaction was stopped by addition $10 \mu \mathrm{l}$ of $2 \mathrm{M}$ sodium hydroxide solution leading to a visible colour change (yellow, positive reaction; pink, no activity). Absorbance readings for the assay were measured at $405 \mathrm{~nm}$ using a spectrophotometer (Spectramax M5, Molecular Devices, USA).

\section{Sodium dodecyl sulphate polyacrylamide gel electrophoresis (SDS-PAGE)}

Proteins were separated by SDS-PAGE consisting of a $10 \%$ $(\mathrm{v} / \mathrm{v})$ resolving gel and 4\% (v/v) stacking gel. Protein samples were diluted in sample buffer with DDT $(40 \mathrm{mM})$, boiled at $95{ }^{\circ} \mathrm{C}$ for $10 \mathrm{~min}$. Samples were electrophoresed at $30 \mathrm{~mA} / \mathrm{gel}$ until the front dye had left the gel $(\sim 1 \mathrm{~h})$. A protein marker was also loaded into one of the lanes of the gel. Gel running buffer was used in electrophoresis. Gels were placed in Coomassie stain for $20 \mathrm{~min}$. Then the destaining solution was applied on the gel 4-5 times for 20 min until the protein bands were visible.

\section{Immunoblot analysis}

The production of SAP2SAG1 protein in the culture supernatant was determined using immunoblot analysis. Proteins were transferred from a $10 \%$ SDS-gel to an Immobilon-P Polyvinylidene Difluoride (PVDF) membrane by the electroblotting system (Biometra) at a current of $4 \mathrm{~mA} / \mathrm{cm}^{2}$ of gel for $90 \mathrm{~min}$. After transfer, the membrane was incubated for one hour at $37^{\circ} \mathrm{C}$ in a blocking solution $(5 \%$ (w/v) milk powder in PBST, $20 \mathrm{mM}$ Tris$\mathrm{HCl} \mathrm{pH} \mathrm{7.5).} \mathrm{This} \mathrm{was} \mathrm{then} \mathrm{replaced} \mathrm{with} \mathrm{a} \mathrm{blocking}$ solution containing the primary monoclonal antibody $(\mathrm{mAb})$ LT8.2 (1:2000) in the blocking solution and incubated for one hour with gentle agitation at $37^{\circ} \mathrm{C}$. The membrane was then washed four times for 5 min with $1 \times$ PBST at room temperature before goat anti-mouse IgG HRP- linked1:2000-1:5000 (DAKO, Hamburg, Germany) was added in blocking solution and incubated for one hour at $37^{\circ} \mathrm{C}$. Three times washes for $5 \mathrm{~min}$ were 
carried out with $1 \times$ PBST and two with $1 \times$ PBS. The blot was incubated and exposed to X-ray films with solutions from the SuperSignal West Pico Chemiluminescent Substrate Kit (Fischer Scientific, Loughborough, UK).

\section{Immunofluorescence microscopy}

Leishmania cell culture samples were prepared and fixed on a 10 well-masked slide. Each sample well on the slide was prepared by washing with $50 \mu \mathrm{l}$ of $70 \%$ ethanol followed by the application of $20 \mu \mathrm{lof} 0.1 \mathrm{mg} / \mathrm{ml}$ polylysine in $1 \times$ PBS and incubation at room temperature for 15 min. After the incubation was completed each well on the slide was washed with $50 \mu$ per well $1 \times$ PBS solution twice. $20 \mu \mathrm{l}$ of total cell culture or cell culture supernatant in a cell density range of $1-2 \times 10^{7}$ cells $/ \mathrm{ml}$ was fixed to each well with $20 \mu \mathrm{l}$ of $4 \% p$-formaldehyde solution by incubation for $15 \mathrm{~min}$ at room temperature. After the incubation was completed each well was washed once for $15 \mathrm{~min}$ at room temperature with $50 \mu \mathrm{l}$ per well $1 \times$ PBS solution, $50 \mathrm{mM} \mathrm{NH}_{4} \mathrm{Cl}, 0.1 \%$ Saponin. $50 \mu \mathrm{l}$ per well of blocking buffer $(1 \times$ PBS solution, $2 \%$ Bovine Serum Albumin (BSA), $1 \times$ PBS, $0.1 \%$ Saponin) was applied to the wells and incubated for further $15 \mathrm{~min}$ at room temperature. $20 \mu \mathrm{l}$ of the primary antibody mAb LT8.2 in a 1:40 dilution in blocking buffer was applied for $1 \mathrm{~h}$ at room temperature followed by two wash steps with $50 \mu \mathrm{l}$ per well $1 \times$ PBS solution. Then the wells were incubated with $20 \mu \mathrm{l}$ per well of a 1:500 dilution of the secondary antibody (goat anti-mouse $\operatorname{IgG}$-conjugated fluorescent tag) in blocking buffer at room temperature for $1 \mathrm{~h}$. The slide was washed three times with $50 \mu \mathrm{l} 1 \times$ PBS solution. $10 \mu \mathrm{l}$ Mowiol/DABCO solution was applied to each well before the slide was sealed with a coverslip and left to dry for 15 min. Fluorescence was detected using an Epifluorescence microscope at $60 \times$ magnification.

\section{Results}

\section{Generation of pLPhSAP2SAG1 and transfection of $L$. tarentolae promastigotes}

A 7984 bp fragment was isolated from pLEXSY-ble2.1 cleaved with $\mathrm{NcoI}+$ NheI. pSSUPacSAP2SAG1 was cleaved by $\mathrm{NcoI}+\mathrm{XbaI}$ and the $3386 \mathrm{bp}$ and $3164 \mathrm{bp}$ fragments isolated, respectively (Fig. 1). pLPhSAP2SAG1 was produced from ligation of $3386 \mathrm{bp}$ with the $7984 \mathrm{bp}$ fragments. pLPhSAP2SAG1 was transformed into $E$. coli DH5 $\alpha$, amplified, isolated and cleaved with BamHI, NotI and HindIII to confirm the identities of the plasmids (Fig. 2A). To generate Linear DNA Fragments for Electroporation, pLPhSAP2SAG1 was cleaved with SwaI to

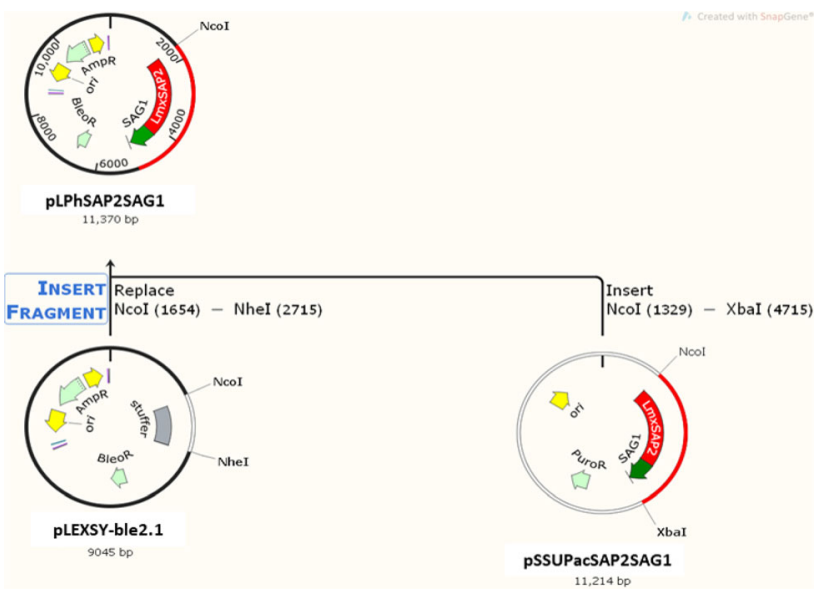

Fig. 1 Generation of pLPhSAP2SAG1 from pLEXSY-ble2.1

isolate the $7207 \mathrm{bp}$ under a sterile condition. Figure 2B show the confirmation of the fragment size. Isolated linear fragments were transfected into $L$. tarentolae promastigotes. Turbid wells were obtained from 1:40 dilution of the electroporated cells were 5 for PhleoSAP2SAG1 on 96 well plates. Four positive cell lines were chosen to scale up in $10 \mathrm{ml}$ cultures for further analysis.

\section{Confirmation of integration of constructs into the $18 \mathrm{~S}$ rRNA gene locus by polymerase chain reaction (PCR)}

To test the correct integration of the construct into the rRNA gene locus specific oligonucleotide primers were chosen for PCR to amplify fragments of distinctive size. Table 1 showed the amplification of an $862 \mathrm{bp}$ DNA fragment proved the correct integration of SAP2SAG1 construct into the rRNA gene locus (Fig. 3A). In a second PCR, a $696 \mathrm{bp}$ amplicon confirmed the fusion of the secreted acid phosphatase gene (SAP2) to the SAG1 coding region (Fig. 3B). L. tarentolae wild type, which served as a negative control in the PCR reactions.

\section{Detection of secreted acid phosphatase activity in the culture supernatants of recombinant $L$. tarentolae Promastigotes}

Secreted acid phosphatase (SAP2) activity in culture supernatants was used to determine the presence of the recombinant fusion proteins. A quantitative spectrophotometric assay was performed to measure the SAP2 activity from different culture supernatants of recombinant $L$. tarentolae promastigotes grown in SDM79 medium supplemented with $10 \%$ iFCS and $7.5 \mu \mathrm{g} / \mathrm{ml}$ hemin. For comparison purposes, the supernatants of two controls, $L$. mexicana wild type (positive control) and $L$. tarentolae 


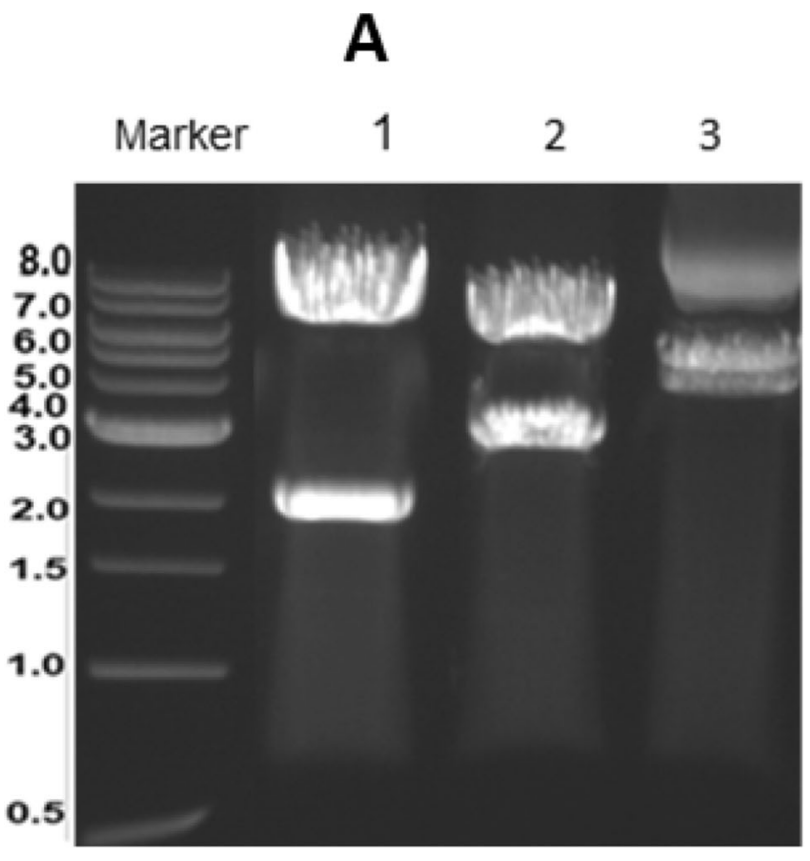

B

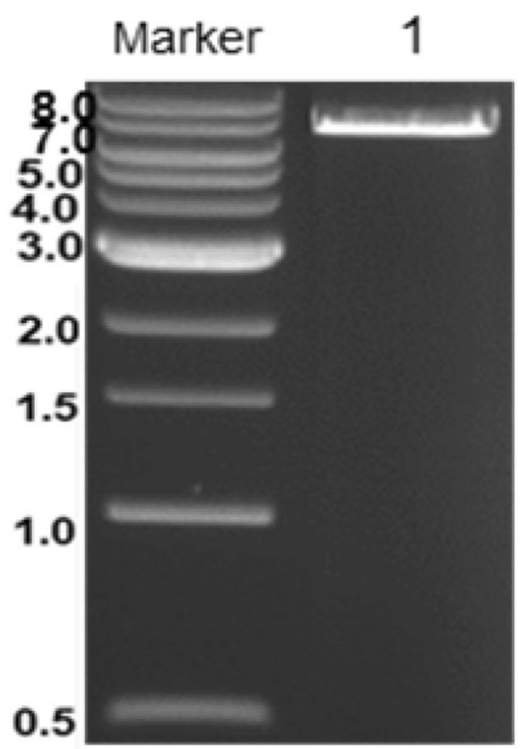

Fig. 2 (A) Restriction analysis of pLPhSAP2SAG1. Lanes 1,BamHI (2223 bp and 9147 bp); lanes 2, NotI (3396 bp and 7974 bp); lanes 3, HindIII, (5094 bp and $6276 \mathrm{bp}$ ). DNA size marker in kb.
(B) Generation of linear DNA for electroporation. pLPhSAP2SAG1 cleaved with SwaI resulted in 7207 bp DNA
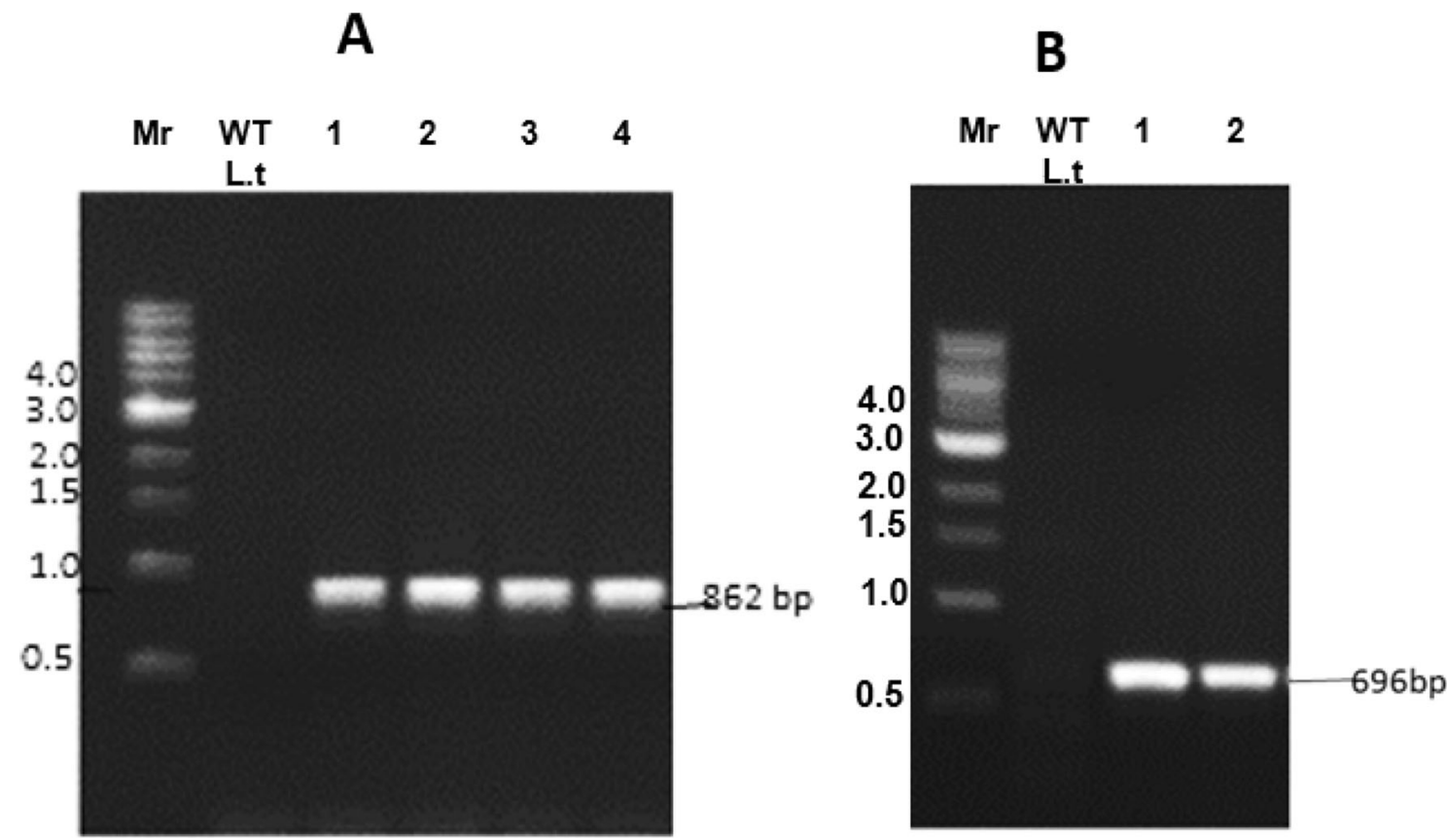

Fig. 3 PCR verification for correct integration of PhleoSAP2SAG1 into the rRNA gene locus of $L$. tarentolae. (A) Integration of SAP2/ SAG1 construct into the $L$. tarentolae rRNA gene locus. Lanes 1-4, $862 \mathrm{bp}$ amplicon reflects the correct integration. (B) Fusion of SAG1

wild type (negative control), were also measured. Four cell lines (A11, E11, F7, F11) of L. tarentolae promastigotes transfected with PhleoSAP2SAG1 presented the enzymatic to SAP2 for PhleoSAP2SAG1. Lanes 1 and 2, the 696 bp fragments, confirmed the fusion of SAG1 to SAP2. $L . t$ WT is $L$. tarentolae wild type (negative control). DNA size marker in $\mathrm{kb}$ in A and B

activity of acid phosphatase activity (Fig. 4). To determine the levels of recombinant protein in supplemented culture supernatants, the cells were grown over three days and the 


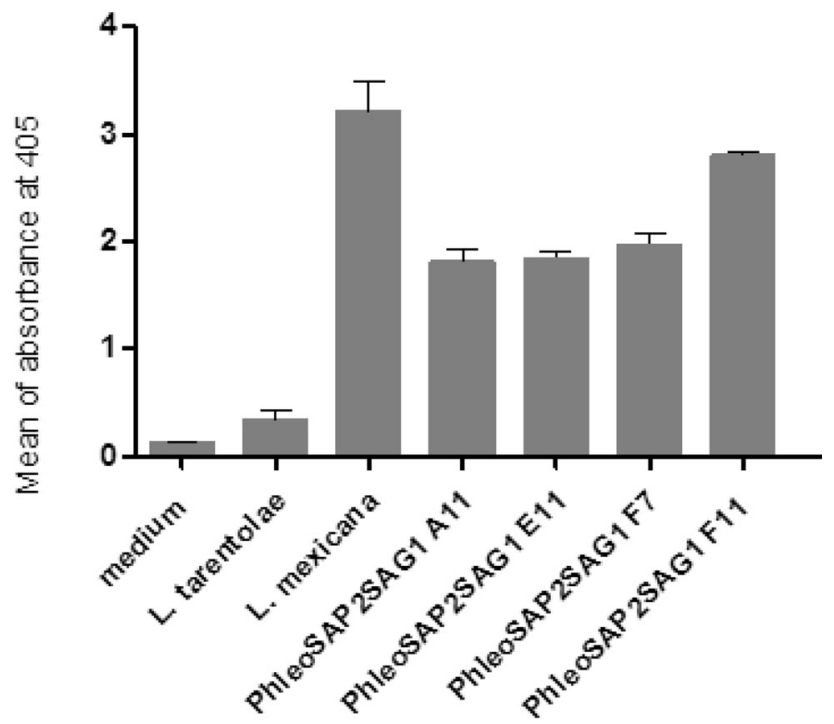

Clones cultured in supplemented SDM79

Fig. 4 Secreted acid phosphatase activity in supplemented culture supernatants of Leishmania promastigotes. L. tarentolae promastigotes transfected with four clones of PhleoSAP2SAG1. L. mexicana and $L$. tarentolae were used as positive and negative controls, respectively. Measurements were done in triplicate

cell density and enzymatic activity were measured. On day one a low cell density and enzymatic activity were found. The second and third day presented similar enzymatic activity, but the cell density on day three suggested that the cells were already in the stationary growth phase (Fig. 5A and $\mathrm{B})$. Therefore, for the following experiments, the second day of culture was selected to enrich the fusion protein from the culture supernatants of recombinant cells. To make the purification of the fusion protein from culture supernatants as simple as possible, it was attempted to grow the promastigotes in non-supplemented SDM79 medium. Four $L$. tarentolae cell lines transfected with PhleoSAP2SAG1, L. tarentolae and L. mexicana wild type were grown in supplemented and a non-supplemented SDM79 medium to determine the enzyme activity in the media. When compared, no activity was observed from promastigotes cells growing in non-supplemented media for two days; in contrast, growing cells in supplemented media showed high enzymatic activity (Fig. 6).

\section{Detection of recombinant protein in culture supernatants by immunofluorescence microscopy}

Immunofluorescence analysis of cells and cell culture supernatants were used to detect the SAP2SAG1 fusion protein secreted by $L$. tarentolae promastigotes into their culture supernatants by using the mAb LT8.2. L. mexicana wild type promastigotes secrete large amounts of secreted acid phosphatase, served as a positive control. No material
A

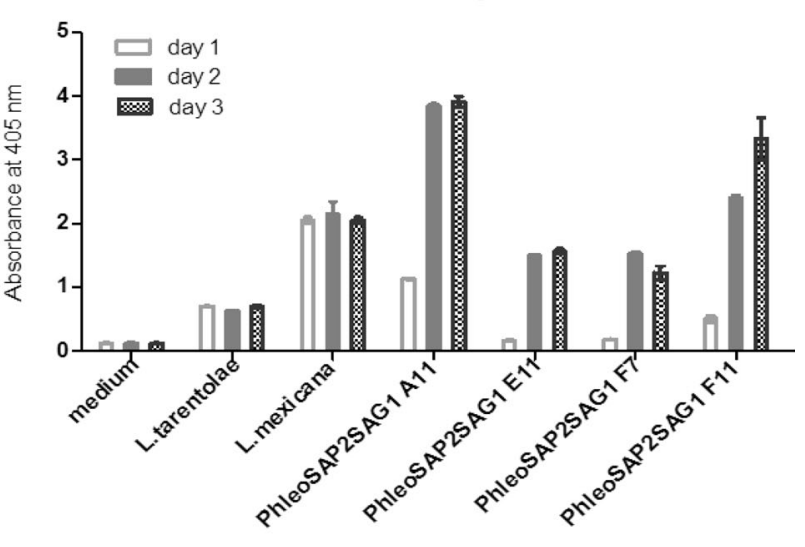

Clones cultured in supplemented SDM79

B

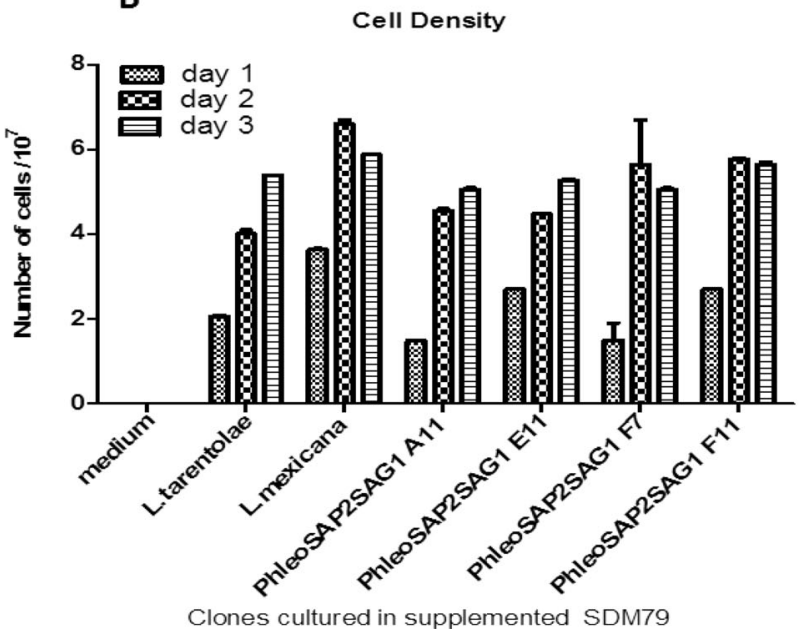

Fig. 5 Time course of secreted acid phosphatase activity in culture supernatants. (A) Enzyme activity of recombinant L. tarentolae promastigotes from supplemented culture supernatants followed over three days. Measurements were done in triplicate. (B) Cell density over three days of incubation

detectable with mAb LT8.2 from $L$. tarentolae promastigotes (negative control) in their culture supernatants. Supernatants from $L$. tarentolae promastigotes transfected with PhleoSAP2SAG1 showed green fluorescence less than those from L. mexicana in their culture supernatant (Fig. 7).

\section{Detection of recombinant proteins in culture supernatants by immunoblot analysis}

Immunoblot analysis was used to detect the recombinant SAP2SAG1 fusion protein in the sediment of culture supernatants of recombinant $L$. tarentolae promastigotes after purified by ultracentrifugation using mAb LT8.2. Strong bands were detected by mAb LT8.2 around $175 \mathrm{kDa}$ in culture supernatants of $L$. tarentolae 
wo supplemented

non-supplemented

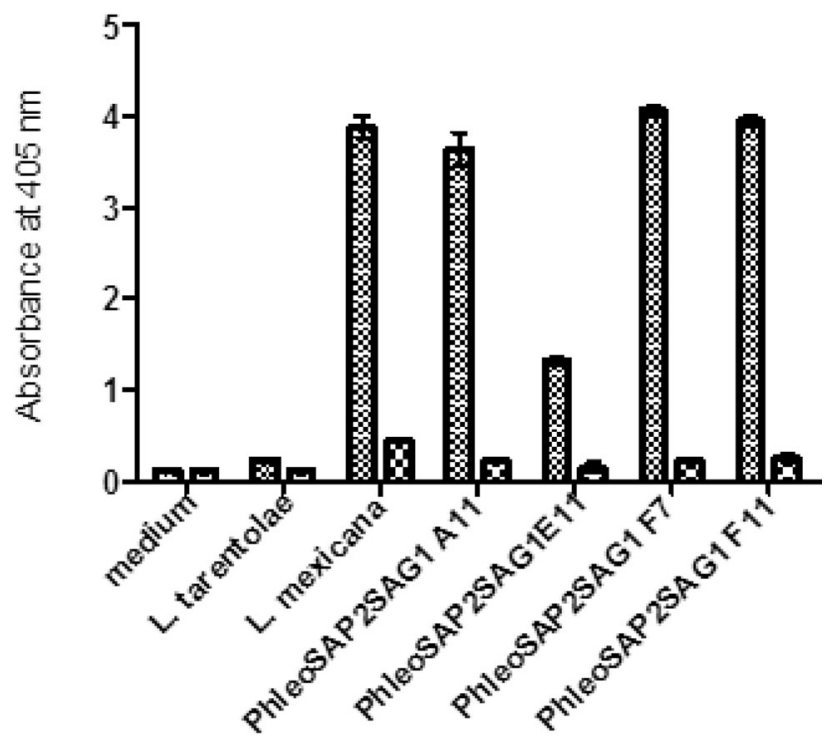

Cultured Clones

Fig. 6 Comparison of secreted acid phosphatase levels from culture supernatants of Leishmania promastigotes grown in supplemented and non-supplemented cultures. WT L. tarentolae and L. mexicana were used as negative and positive controls, respectively. Measurements were done in triplicate

promastigote transfected with the PhleoSAP2SAG1 construct. L. mexicana samples showed a band of $89 \mathrm{kDa}$ corresponding to SAP1 (Martin Wiese et al. 1999), while no band was detectable when using $L$. tarentolae as a negative control (Fig. 8 and 9).

\section{Discussion}

\section{DNA constructs generation}

Because of its unique features, $L$. tarentolae has previously been used to express secreted proteins like easy growth of parasites, protein purification from culture, and the presence of post-translational modifications (Basile and Peticca 2009; Kovtun et al. 2011). We have constructed a novel filamentous protein expression system using a DNA cassette for integration into the $18 \mathrm{~S}$ ribosomal RNA gene locus using the pLEXSY-ble2.1 expression vector. Previously, different proteins have been successfully expressed in high levels using pSSU constructs in Leishmania, e.g. $\beta$ galactosidase and green fluorescent protein (Mißlitz et al. 2000). Human laminin-332 and c-reactive proteins were produced into the culture supernatant of $L$. tarentolae (Dortay et al. 2011; Phan et al. 2009). SAP2 from $L$. mexicana including its $\mathrm{N}$-terminal phosphatase domain, the serine/threonine-rich repeats and the mAb LT8.2 epitope was used as a carrier for $T$. gondii proteins, SAG1, which were genetically fused to its $\mathrm{C}$-terminus.

\section{Efficiency of electroporation}

Trypanosomatids can be efficiently transfected by electroporation of in vitro cultivated promastigotes (Beverley and Clayton 1993). Moreover, the selection of recombinant parasites can easily be performed using antibiotic resistance genes, such as phleomycin, which also used in this investigation to generate permanent and stable transfectants, linear DNA for chromosomal integration (Beverley and Clayton 1993). However, when using higher DNA amounts homologous integration of multiple copies of the transfected DNA could be observed into the L. tarentolae genome through homologous recombination (Kianmehr et al. 2016). To confirm integration into the small subunit rRNA gene locus of the L. tarentolae genome by homologous recombination diagnostic PCRs were performed. The PCR results proved both the fusion of the SAG1 gene to the SAP2 gene and the integration into the proposed site. It is important to note that transcription in this chromosomal location is under the control of RNA polymerase I, which allows high-level transcription (Teixeira 1998).

\section{Gene expression in L. tarentolae}

SAP of L. mexicana promastigotes was previously expressed in L. donovani (Ilg et al. 1991) and L. major (Martin Wiese et al. 1999). It is easier to isolate and purify recombinant proteins if they are exported outside the cell. In this study, filaments composed of the SAP2SAG1 fusion protein was generated and expressed in $L$. tarentolae. To improve protein yield transfection of $L$. tarentolae with multiple copies of the gene of interest integration into different gene loci could have been attempted (Breitling et al. 2002). The recombinant constructs for gene expression were integrated into the $18 \mathrm{~S}$ small subunit ribosomal RNA gene locus to achieve strong transcription. Interestingly gene regulation, in trypanosomatids, occurs on a post-transcriptional level through intergenic untranslated regions (UTRs) (Clayton 1999). Therefore, the choice of suitable UTRs is crucial for the construction of an efficient expression cassette suitable for large-scale recombinant protein production (Breitling et al. 2002). The commercial plasmid, pLEXSY-ble2.1, contains three different untranslated regions (UTR1, UTR2 and UTR3), which were supposed to increase the expression level of recombinant proteins in $L$. tarentolae. The LEXSY system has been successful previously used to express small secreted proteins, like IFN- $\gamma$ (Davoudi et al. 2011) and IL-29 (Taromchi et al. 2013). 


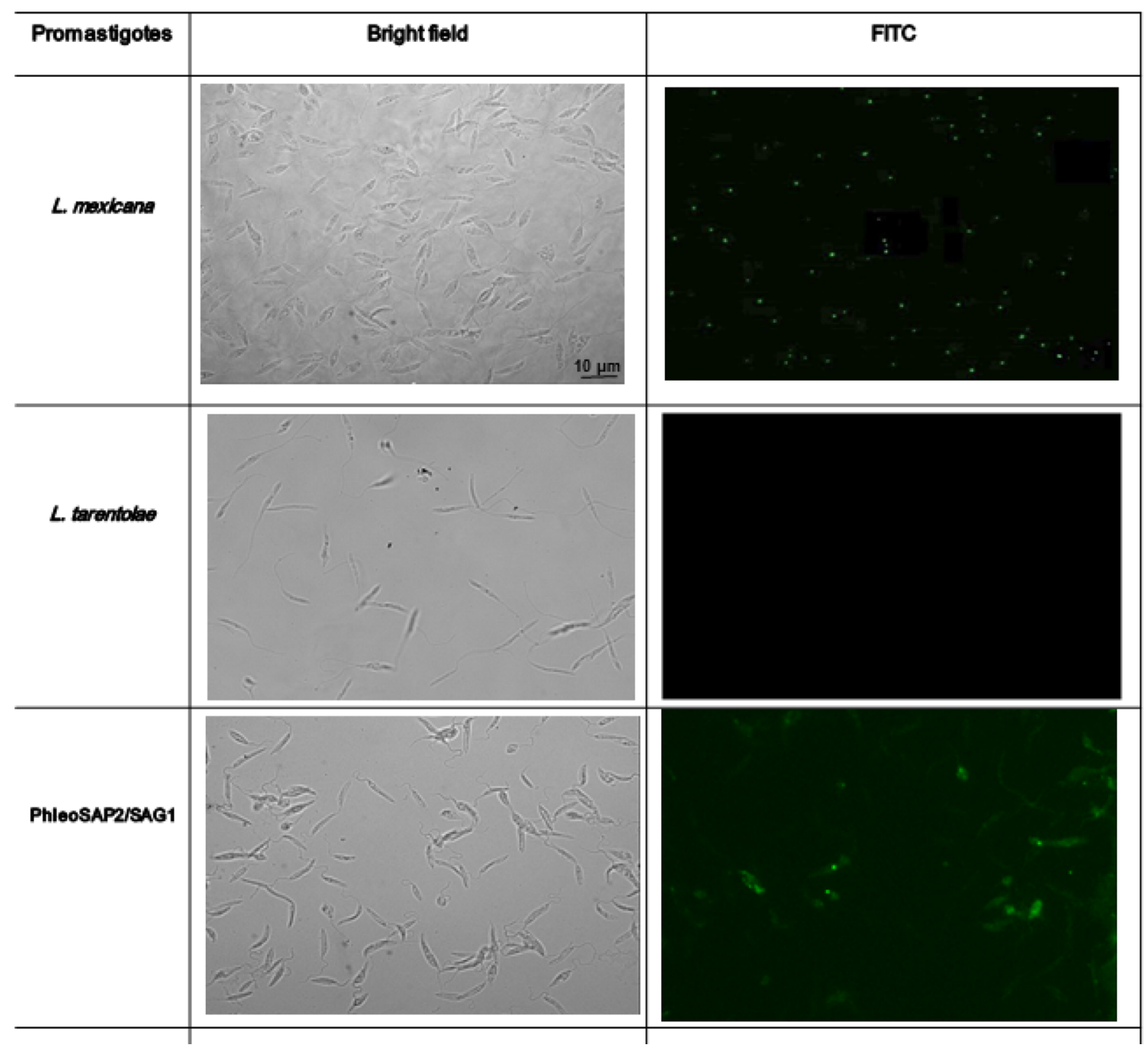
medium using mAb LT8.2 to detect secreted acid phosphatase. Bright field microscopy using $40 \times$ magnification on the left and
Fig. 7 Immunofluorescence analysis of Leishmania promastigotes in

fluorescence microscopy using $488 \mathrm{~nm}$ excitation with FITC filter at the same magnification on the right. Size bar, $10 \mu \mathrm{m}$

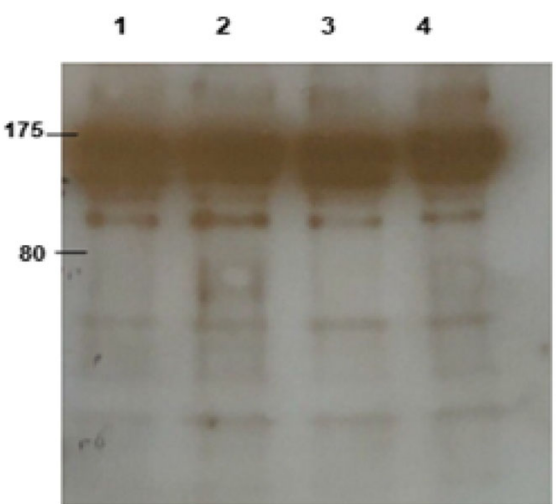

5

6

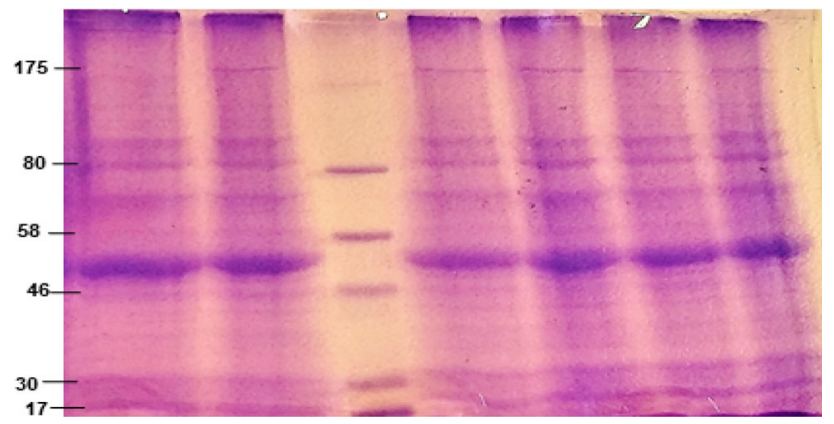

Fig. 8 Coomassie-stained 10\% SDS-PAGE of $L$. tarentolae carrying PhleoSAP2SAG1. Lane 1, L. tarentolae (negative control); lane 2, $L$. mexicana (positive control); lane 3-6, PhleoSAP2SAG1 (A11, E11, F7, F11). Protein size marker in $\mathrm{kDa}$
Fig. 9 Immunoblot analysis of $L$. tarentolae carrying PhleoSAP2SAG1. mAb LT8.2 immunoblot of promastigote cells. Lane 1-4, PhleoSAP2SAG1 (A11, E11, F7, F11); lane 5, L. tarentolae (negative control); lane 6, L. mexicana (positive control). Protein size marker in $\mathrm{kDa}$ 
Table 1 Oligonucleotide sequences used in PCR and expected fragment sizes for each PCR reaction

\begin{tabular}{lll}
\hline Primers & Sequence & Size (bp) \\
\hline LeishSSU.Fw1 & 5'-GATCTGGTTGATTCTGCCAGTAG-3' & 862 \\
pLexyup1.Rv1 & 5'-CCTACGTCAATCGCAGACCT-3' & \\
SAP2MOD2C.Fw2 & 5'-AGCGACGTCCCTTCCTTCAA-3' & 696 \\
SAG1.Rv2 & 5'-GTGAAGTGGTTCTCCGTCGG-3' & \\
\hline
\end{tabular}

\section{Secreted acid phosphatase activity}

An advantage of the SAP2 fusion protein system is the ease of detecting protein expression by a phosphatase reporter assay directly from cell culture supernatants. The expression level of the SAP2 fusion proteins in L. tarentolae was tested by measuring the secreted acid phosphatase activity in the culture supernatant. As long as SAP2 is the only enzyme in the supernatant, we can calibrate the percent protein expressed in the supernatant based on enzyme activity at $405 \mathrm{~nm}$ wavelength (Zhang et al. 1992). A $1.041 \mathrm{~mol} / \mathrm{ml}$ proximate concentration of the SAP2SAG1 fusion proteins from the culture supernatant of $L$. tarentolae growing in $10 \%$ iFCS. The secretion signal sequence of L. mexicana secreted acid phosphatase was used to produce different proteins (Basile and Peticca 2009). To avoid interference of proteins, present in iFCS (mainly bovine serum albumin) with the purification of the recombinant protein, recombinant parasites were grown in non-supplemented media. No phosphatase activity was detectable in culture supernatants from these cells confirming the importance of iFCS in the culture medium.

\section{Immunofluorescence analyses}

The detection of the recombinant proteins by immunofluorescence confirmed the successful secretion of the recombinant proteins into culture supernatants. When comparing the amount of green fluorescence obtained from L. mexicana wild type, which served as a positive control, SAP2SAG1 expressed using pLEXSY-ble2.1 revealed filamentous structures along with stronger green fluorescence signals. SAG1 is a prototypic member of a superfamily of surface glycoproteins, which is mostly located at the surface of $T$. gondii (He et al. 2002). This makes it more likely to be secreted normally through the secretory pathway of other protozoan parasites like L. tarentolae.

\section{Immunoblot analyses}

Immunoblot analyses results of SAP2SAG1 using the $\mathrm{mAb}$ LT8.2 showed strong bands around175 $\mathrm{kDa}$ from supernatants purified by ultracentrifuge. The signal is most likely derived from fusion protein retained in the flagellar pocket or from protein in transit in the secretory pathway. The $175 \mathrm{kDa}$ bands correspond to the full-length recombinant fusion protein. Generally, proteolytic maturation occurs in secretory or transport vesicles carrying proteins from the trans-Golgi network to the cell surface (Lodish et al. 2001). The modifications of SAP2 protein form a filamentous complex with long serine/threonine-rich regions, and $\mathrm{N}$-linked glycans on the $\mathrm{N}$-terminal phosphatase domain which are highly glycosylated might protect the protein against proteolytic degradation (Wiese et al. 1995).

\section{Conclusions}

The data gathered by the use of enzyme activity measurement, immunoblot and immunofluorescence analyses in this study provide convincing evidence that the proteins of interest have been expressed successfully. Protein amounts obtained for SAP2SAG1 using pLEXSY-ble2.1 were not determined because of too high serum contaminations in the samples. However, it can be said from the results from the Coomassie-stained gels that the amount of protein is more in the $\mu \mathrm{g}$ than in the $\mathrm{mg}$ range. To improve the protein expression levels of the filamentous fusion proteins, further investigation needs to be done to increase the expected efficiency of $L$. tarentolae production of $T$. gondii protein SAG1.

Acknowledgements I would like to thank Prof. Craig W Roberts and Dr. M. Wiese (Strathclyde Glasgow University/Uk) for their assistance with protein expression and purification.

Authors' contributions MW analyzed and interpreted the immunoblot and immunofluorescences data. CWR examination was a contributorin writing the manuscript.

Funding This study was funded by the Iraqi ministry of higher education and scientific research/Baghdad University.

\section{Declarations}

Conflict of interests No competing interests in this article. 


\section{References}

Abdizadeh R, Maraghi S, Ghadiri AA, Tavalla M, Shojaee S (2015) Cloning and expression of major surface antigen 1 gene of Toxoplasma gondii $\mathrm{RH}$ strain using the expression vector pVAX1 in Chinese Hamster Ovary cells. Jundishapur J Microbiol 8(3):1-10. https://doi.org/10.5812/jjm.22570

Basile G, Peticca M (2009) Recombinant protein expression in Leishmania tarentolae. Mol Biotechnol 43(3):273-278. https://doi.org/10.1007/s12033-009-9213-5

Beverley SM, Clayton CE (1993) Transfection of Leishmania and Trypanosoma brucei by electroporation. In: Hyde JE (ed) Protocols in molecular parasitology. Humana Press, New Jersey, pp 333-348

Breitling R, Klingner S, Callewaert N, Pietrucha R, Geyer A, Ehrlich G, Hartung R, Müller A, Contreras R, Beverley SM, Alexandrov K (2002) Non-pathogenic trypanosomatid protozoa as a platform for protein research and production. Protein Expr Purif 25(2):209-218. https://doi.org/10.1016/S1046-5928(02)00001-3

Clayton CE (1999) Genetic manipulation of Kinetoplastida. Parasitol Today 15(9):372-378. https://doi.org/10.1016/S0169-4758(99) 01498-2

Davoudi N, Hemmati A, Khodayari Z, Adeli A, Hemayatkar M (2011) Cloning and expression of human IFN- $\gamma$ in Leishmania tarentolae. World J Microbiol Biotechnol 27:1893-1899. https://doi.org/10.1007/s11274-010-0648-4

Dey R, Natarajan G, Bhattacharya P, Cummings H, Dagur PK, Terrazas C, Selvapandiyan A, McCoy JP, Duncan R, Satoskar AR, Nakhasi HL (2014) Characterization of cross-protection by genetically modified live-attenuated Leishmania donovani parasites against Leishmania mexicana. J Immunol 193(7):3513-3527. https://doi.org/10.4049/jimmunol.1303145

Dortay H, Schmöckel SM, Fettke J, Mueller-Roeber B (2011) Expression of human c-reactive protein in different systems and its purification from Leishmania tarentolae. Protein Expr Purif 78(1):55-60. https://doi.org/10.1016/j.pep.2011.03.010M4-Citavi

He X, Grigg ME, Boothroyd JC, Garcia KC (2002) Structure of the immunodominant surface antigen from the Toxoplasma gondii SRS superfamily. Nat Struct Biol 9(8):606-611. https://doi.org/10.1038/nsb819

Ilg T, Stierhof YD, Etges R, Adrian M, Harbecke D, Overath P (1991) Secreted acid phosphatase of Leishmania mexicana: a filamentous phosphoglycoprotein polymer. Proc Natl Acad Sci USA 88(19):8774-8778. https://doi.org/10.1006/jmbi.1998.2012

Kianmehr A, Mahrooz A, Oladnabi M, Safdari Y, Ansari J, Veisi K, Evazalipour M, Shahbazmohammadi H, Omidinia E (2016) Purification and characterization of recombinant Darbepoetin Alfa from Leishmania tarentolae. Mol Biotechnol 58(8-9):566-572. https://doi.org/10.1007/s12033-016-9954-х

Kovtun O, Mureev S, Jung W, Kubala MH, Johnston W, Alexandrov K (2011) Leishmania cell-free protein expression system. Methods 55(1):58-64. https://doi.org/10.1016/j.yme th.2011.06.006

Lekutis C, Ferguson DJP, Grigg ME, Camps M, Boothroyd JC (2001) Surface antigens of Toxoplasma gondii: variations on a theme.
Int J Parasitol 31(12):1285-1292. https://doi.org/1 $0.1016 / \mathrm{S} 0020-7519(01) 00261-2$

Lodish H, Lawrence Zipursky S (2001) Molecular cell biology. Biochem Mol Biol Educ 29:126-133

Mißlitz A, Mottram JC, Overath P, Aebischer T (2000) Targeted integration into a rRNA locus results in uniform and high level expression of transgenes in Leishmania amastigotes. Mol Biochem Parasitol 107(2):251-261. https://doi.org/10.1016/S0 166-6851(00)00195-X

Phan HP, Sugino M, Niimi T (2009) The production of recombinant human laminin-332 in a Leishmania tarentolae expression system. Protein Expr Purif 68(1):79-84. https://doi.org/10.10 16/j.pep.2009.07.005

Raymond F, Boisvert S, Roy G, Ritt JF, Legare D, Isnard A, Corbeil J (2012) Genome sequencing of the lizard parasite Leishmania tarentolae reveals loss of genes associated to the intracellular stage of human pathogenic species. Nucl Acids Res 40(3):1131-1147. https://doi.org/10.1093/nar/gkr834

Tang X, Yin G, Qin M, Tao G, Suo J, Liu X, Suo X (2016) Transgenic Eimeria tenella as a vaccine vehicle: expressing TgSAG1 elicits protective immunity against Toxoplasma gondii infections in chickens and mice. Sci Rep 6:1-9. https://doi.org/10.1038/srep29379

Taromchi AH, Kazemi B, Mahmazi S, Bandehpour M (2013) Heterologous expression of human IL-29 (IFN- $\lambda 1$ ) in Iranian Lizard Leishmania. Iran J Biotechnol 11(3):168-174. https://doi.org/10.5812/ijb.12468

Teixeira SM (1998) Control of gene expression in Trypanosomatidae. Braz J Med Biol Res = Revista Brasileira De Pesquisas Médicas e Biológicas/sociedade Brasileira De Biofísica. [et Al.] 31:1503-1516. https://doi.org/10.1590/S0100-879X1998001200001

Wang Y, Yin H (2014) Research progress on surface antigen 1 (SAG1) of Toxoplasma gondii. Parasites Vectors 7(1):180. https://doi.org/10.1186/1756-3305-7-180

Wiese M, Ilg T, Lottspeich F, Overath P (1995) Ser/Thr-rich repetitive motifs as targets for phosphoglycan modifications in Leishmania mexicana secreted acid phosphatase. EMBO J 14(6):1067-1074

Wiese M, Görcke I, Overath P (1999) Expression and species-specific glycosylation of Leishmania mexicana secreted acid phosphatase in Leishmania major. Mol Biochem Parasitol 102(2):325-329. https://doi.org/10.1016/S0166-6851(99)00095-X

Wilson VCLC, Southgate BA (1979) Lizard Leishmania. In: Lumsden WHR, Evans DA (eds) Biology of the kinetoplastida, vol 2. Academic Press, London, pp 241-268

Zhang ZY, Clemens JC, Schubert HL, Stuckey JA, Fischer MW, Hume DM, Saper MA, Dixon JE (1992) Expression, purification, and physicochemical characterization of a recombinant Yersinia protein tyrosine phosphatase. J Biol Chem 267(33):23759-23766

Publisher's Note Springer Nature remains neutral with regard to jurisdictional claims in published maps and institutional affiliations. 